\title{
Role of Bollywood Cinema in Shaping Youngerstersfor Social Awareness
}

\author{
Dr. Neeraj Khattri \\ Professor and Director \\ Institute of Media Studies \\ Shri Ramswaroop Memorial University, IN \\ neerajkhattri101@gmail.com \\ \& \\ Arshita Singh \\ Researcher \\ arshitasingh74033@gmail.com
}

\begin{abstract}
The potential of cinema from thebeginning is used in such a way which benefits the society.The role of Cinema on society has been recognized from the very beginning of Cinema itself. It has been seen that children who cannot get good education but can easily acquire bad habits- buy two anna tickets and watch cinema daily. The society needs to be made aware of the influence of Cinema on the social and moral turnout of the viewers. An attempt has been made to evaluate the social implications of Cinema which is the powerful medium of information, education and entertainment results in the process of opinion building in various social groups. Community is very much influenced by the cinema and they inhale psychological, cultural, sociological changes along with the drastic changes in lifestyle. In recent times cinema often started to show some sensitive issues related to menstruation, women harassment, drug consumption, sexualviolence, etc. Before these movies no one wants to talk about these things they consider it as taboo for society, people never want to talk about erectile dysfunction sanitation, menstrual hygiene etc but some director and actors raise these issue and motivate people to stand for themselves. Movies like Shubh Mangal JaydaSavdhaan,Toilet ek prem Katha, Phullu and soon address such issues and give courage to talk about that.Through this research paper the attempt was made to analyze the effect of cinema on people and how people accept them. This research also tries to show that movies are not just for entertainment purpose or for commercial success but it also tries to raise social issues and stigma.
\end{abstract}

KEYWORDS: Cinema, Community, Society, Revolution, Entertainment, Women Empowerment,Impact, Social Awareness.

Article Received: 10 August 2020, Revised: 25 October 2020, Accepted: 18 November 2020

\section{INTRODUCTION:}

Cinema is the most composite art form in the present world.It is a worldwide truth that Cinema is a powerful mirror of society. It mirrors the revolutions, cultural tensions and new trends that are surfacing in society in an interesting ways. In the modern day there are very few who would reject Cinema and label it as a social evil. Cinema is basically a motion picture theatre which gives entertainment but it is beyond entertainment which gives messages, motivates and keeps rising social issues. Cinema has very broad reach which have different categories and it is totally depend on viewer that what they want to see or know about.India's first Prime Minister Pandit Jawaharlal Nehru recognized the potential of cinema from the very beginning itself and wanted to use the medium in a way which benefits the society.

Once Pandit Jawaharlal Nehru said that, "I am far from satisfied at the quality of work that has been done. Motion pictures have become an essential part of modern life and they can be used with greater advantage for educational purpose so far greater stress has been laid on a type of film, which presumably is supposed to be entertaining, but the standard or quality of which is not high. I hope that the industry will consider now in terms of meeting the standards and aiming at producing high-class films that have educational and social values. Such films should receive the cooperation and not only of the public but also of the state."

Thus, there are two ways in which the nationalist leadership approached cinema. First, as "low art" which aimed to provide vulgar entertainment to the masses and second as a mode of mass communication which can be used for instilling and propagating good values among the people. The vision of Pandit Jawaharlal Nehru held ground for quite some time and during those early days the purpose of cinema was not entertainment but education and value building amongst societies. 
The role of Cinema on society has been recognized from the very beginning of Cinema itself.The bioscope-cinema Tamasha is becoming very popular in India and South Asia. We have seen that children aged eight to ten years- who cannot get good education but can easily acquire bad habits- buy two anna tickets and watch cinema daily. We have even seen that because of this habit, students of Sanskrit are selling lemonade soda inside in this situation it is imperative for the government to exercise control over cinema".

In a 1963 report for the United Nations Educational, Scientific and Cultural Organization looking at Indian Cinema and culture, the author $\mathrm{Mr}$. BaldoonDhingra quoted a speech by Prime Minister Nehru who stated, "The influence in India of films is greater than newspapers and books combined."

Youth are the young minds of a nation and its future citizens on whose shoulders rest the responsibility to shape the future of the country. These young minds are the most vulnerable and susceptible to influence of cinema.Nowadays, parents allow kids to watch films as it gives them a little breathing space, but it can make a huge effect in a child's mental development. If regulated films can teach youth many skills in an easy and enjoyable manner such as language skills, moral values, difference between right and wrong, it can act as a social tool which can help to prepare the child for the big bad worldmovies like aamdani atthanni kharacha rupaiya which shows the issue like how Indian society wants to limit women's, the conventional thinking that it is the duty of men to work outside and earn money while women have to be in kitchen and can do only household work this kind of movies shows real face of society and help to break these orthodox also give courage and motivate people to go against these conservative thinking. 3 Idiots is another example of cinema which portrays the value of choosing career out of passion than being forced by the parents and society, it also helps to aware students as well that student's marksheet, class performance does not reflectbest future so don't run behind it, you just have to try excellence first and success will come automatically.

On the other hand, there is conclusive evidence that films for young's have become significantly more violent in recent years and are contributing in inculcating negative values in the youth and accordingly shapes their community.

Recently the supremacy of the Cinema industry has become ingrained into our society. Usually there is not just one theater in any particular town, but now half a dozen or more are present. Each one showing a new hit films, which is not contained within the theater walls, but is marketed through $\mathrm{t}$-shirts, posters, Happy Meals, and children's toys. The idea is not just to see the films, but rather become the movie. It is amazing to see how this new culture, driven by entertainment and specifically the contemporary cinema, has developed. One thing cannot be denied in the midst of it, that while movies are becoming more a part of our culture, they are at the same time unavoidably conveying certain beliefs and values that have been created as a result of this shift in focus.

William Romanowski clarifies this by posing the question in his book, Eyes Wide Shut, "Does the entertainment media reflect or shape society?" He follows with explanation to argue that a popular art reflects society is to oversimplify what is really a complex process. In this way, the popular arts contribute to the power of culture to shape community and society. Therefore, film, as a main component of the popular arts, is portraying and reflecting certain values of the culture it was created in, which can lead to certain dangers. As films engage viewers, these cultural norms are infiltrating their minds. And while at times it may be obvious, usually this process of formulating one's worldview by way of the assumptions about life being portrayed in the movie is being absorbed unconsciously.

The problem is not becoming immersed in a story or film being a cultural communicator but rather the immediate problem is the danger that arises when the viewers are ignorant or apathetic to the power these films possess in shaping one's own world view and the often-distorted values that are being presented to the audience. Inevitably, we will be drawn into the story that is being presented on screen or else it would not be a very enjoyable few hours. But the responsibility of the audience is to be aware that while a film may allow us the freedom to escape the reality of our own life temporarily, the life we are entering is often idealized and comes with its own set of skewed values and beliefs.

These misrepresentations could unconsciously assimilate in our minds and become a part of our way of thinking about reality and life if we do not make the distinction. This is what majority of the culture has fallen into, and that is why Romanowski makes the point to say that popular arts are not just a reflection of community society, but rather they are a byproduct of a culture they helped to create. Some of these distortions include the exaltation of individualism and the powerful, self-sufficient hero who needs no one. Not only are genders stereotyped such as the family and religions are also defined in stereotypical ways.

The direction, in which Film Industry and Cinema are moving today, has generated enormous social tension to which we have not been able to find appropriate 
solutions. Although so many researcheshave been done on the positive and negatives role of Cinema on Society. If we talk about influence so, cinema is basically convinced real life or real mentality of society while society get convinced by movies.

Cinema have been very interactive medium to convey social awareness or to rise social issues it helps people to change their mentality on issues like child labor, caste discrimination, racism, women empowerment and so on. Along with rise of social issues cinema also educate people.Cinema also give us stories which was related to our history. At first it gives us information and on the other hand it entertains us by giving a chance to explore past in an easy way. Mostly history related movies are fact based and depicts reality and it connect modern people with past generation. A good example is Tanhaji which shows our history that how people sacrifices their life for freedom and how we get this freedom.This kind of movies also help to show our culture,rituals, and about the word that how things are going before innovation.

Cinema cannot suddenly change people brooding but can generate notable impact for sure movies like Lajja,Damini, Thappad, Pinketc which are based on women empowerment, primitive thinking of people, social stigma and against patriarchal society reflect the matter and make us familiar with them.

Cinemas have determinedly dealt with the problems of the society and brought out the shadiest secrets of the world as it is today. The thought that a movie always equals entertainment is but a myth.It is clear that cinemas are unquestionably reflective of the society that we live in, the strong link between "reel" and "real" is here to stay and cinema influenced our lifestyle vice versa as well.

An attempt has been made to evaluate the social implications of Cinema which is the powerful medium of information, education and entertainment results in the process of opinion building in various social groups. Actually, cinema is the medium of cinema reciprocates in bringing a social change.It means that community are very much influenced by the cinema and they inhale psychological, cultural, sociological changes along with the drastic changes in lifestyle, behavior and so on.

\section{Objective:}

1) To analyze the impact of cinema in creating social awareness.

2) To find how cinema help us to shape our community and society.

3) To observe how citizens of country consume cinema.

4) To identify how cinema play role in our educational, political and moral life.

\section{Review of Literature:}

Cinema is also popular educational foundation of the country. Ramachandra Guha noted social historian of Indian states, "Feature films are the great historian of Indian states, cutting across the social divides of caste, class, religion, gender and language." (R. Guha, 2007).

Social issues such as farmer sufferings, untouchability came to limelight through more meaningful cinema in 1930 s, just about the period when India was experiencing economic and social reforms alongside the struggle for freedom, which provided themes to the movies such as Mehboob khan's Mother India (1957) and Bimal Roy's Do BhighaZameen (1953) stated by (Murthy C.S.H.N,2011). This led various movie makers to follow more innovative ways to convey movie with social message which is attributed to the success of movies like Munnabhai MBBS, Taare Zameen Par, Rang De Basanti and many more.

This form of media creates a new wave, both for the movie makers and for audience because movies now have potential to go beyond musicals and entertainment to bring a social message to the big cinema screen. With increasing popularity of electronic media and the phenomenal success of Hindi movies among the Indian diaspora (Dudrah,2006, Uberoi,1998), it is important to study the role of Bollywood movies in the identity construction of the Indian diaspora.

"Movies are a type of communication that is consumed by majority of people not only in India but also internationally,cinema is not only a way to reach out to the masses but also to educate them" (saidAkshay Kumarwhile explaining the value of cinema in an interview with Hindustan times.)

Film toilet ek prem katha aid to encourage clean India campaign by a love story. The constructions of toilet get motivated by the movie and build 24 toilets in 24 hours to promote clean Indiacampaign. Aruhi Jain shares the fact in her article that " $54 \%$ of Indian population still defecates in open,millions of women risk of getting raped every day, 2lakh children die each year of infection from open defecation."'(statement by Ms. A. Kameshwari, in an article of Indian express newspaper.)

"Male sexual health has been taboo subject. Vicky donormovie was a catalyst for this change our society realizes the importance of having a discussion regarding men sexual health.After Shubh Mangal Savdhaan, the number of people coming to infertility clinic for erectile problem has increased".The effect of movie Shubh Mangal Savdhaan, "no doubt, movies like Vicky donor and Shubh mangal Savdhaan create awareness and normalize sensitive 
topics,".(stated in Hindustan times by Dr. Arvind Vaid, a fertility expert).

NGO get motivated by movie Padman and start given training of making sanitary pads to 20 women.Divya rajgopal also write about the success of Padman in economic times and share the fact that $80 \%$ of Indian women do not use pad because of its high price she stated that movies like Padman, Phullu and the $\mathrm{P}$ factor helpIndia for finally witnessing a period of change.She also shares a story of Rohit rajut that how he is contributing by making cheapest napkins from last two decades.("Can a book create movement" written by Ms. Shoma A. Chatterjee who shares a data from different states about menstrual hygiene, in her study she writes about a NGO The Alo female cooperative credit society.)

The narrative and representational aspects of film make it is wholly unique form of art. Moreover, the unique properties of attending the cinema can have decisively position effect on mental health.Cinema attendance can have independent and robust effects on mental wellbeing because visual stimulation can queue a range of emotions and the collective experience of these emotions through the cinema provide safe environment in which experience roles and emotions we might not otherwise to experience.Attending the cinema allow for the exercise of personal preferences and the human need for distinction. (Paper by S C Noah Uhrig entitled, "cinema is good for you: the effect of cinema attendance of self-reported anxiety or depression or happiness").

\section{Research methodology:}

Indian cinema has given best movies that actually manage to bring change in the society.Researcher used qualitative method for finding impact on youngsters. In this study the exploratory research is used to analyze the impact of Bollywood movies on youngster. The analysis of some Bollywood films with social theme has showed that all these films gets success in portraying the less discussed social issues in our society. Film such as Mardani, Toilet ekpremkatha 3 idiots, Thappad, Gulab gang and many more had an actual impact on society.By bringing the purposive sampling of the films was basis of their impact on the youngsters and the awareness these movies created in the society .

\section{Research Findings:}

Basically, cinema is source of entertainment but as per the study it is also an effective source to generate social change and educate people.Cinema is able to raise social issues and guide people about various social issues.It also gives courage to people to come forward and speak about sufferings and social evils. Cinema is also a powerful means for educating people and give them chance to know our culture. Cinema is generally a mirror of society in which we live it effects all kinds of people life, rather its villager, low educated people or a city people.Sometimes it totally changes people perspective on many topic, movies like ShubhMangal JaydaSavdhaan help people to know facts about homosexuals before this movie many people think that its choice to be gay but after that, people understand that its natural biological feature. Movies like Phullu and Padman also encourage many women to use pad and understand the value of menstrual hygiene it also motivates many NGOs to make cheap sanitary pads. These kinds of movies help people to fight with thesocial evils and work for that.This reflects that Cinema is not only way for entertainment and social awareness instead of that it givesemployment to many people.It is powerful weapon to influence people in many ways, it also helped to change social trends of society. Nowadays cinema does not only work for entertainment or commercial profit but most of the time it tackled many diplomatic issues like women empowerment,globalization, human rights etc.

This research also revealed that how realistic cinema influences and shapes the society for better future. The perceptions and opinions the people build about social issues that surrounded our society are largely, if not completely governed by the way they are depicted through method acting. Some movies such as Taare Zameen Par (movie based on the medical condition Dyslexia) conveys a very strong message about mental condition and how love, care and more attention could help the patient to recover and flourish, simultaneously conveying the message that such disabilities should not be looked down upon as a social stigma of mental illness.

Cinema enlarge the frontiers of our knowledge as citizens get knowledge about political, cultural and customs of many countries including economic condition. By this research it is clear that Cinema promotes national integration as the artist. The viewers and other people concerned belong to different castes, religions and gender whereas the impact on citizens is not only positive but also negative because people tend to copy their favorite artists dresses, lifestyle and caricature which often leads to a tragedy.

Cinema is the biggest source of entertainment for all sections of society rich and poor literate and poor section of society. Indian cinema not only plays a significant role in integrating society but also imparts human values on people such as honesty, hard work, sympathy, charity, brotherhood. Almost all movies have stories in which goodness is rewarded and wickedness is punished. There is justice and hope in 
almost every Bollywood movie. This has great influence on people especially the young boys who want to become like the hero.

In patriarchal society like India, its not considered good for girls to take part in sports such as boxing, hockey, cricket, it's hard to believe that women can take part in these sports. But situation is changing now in society and also in films like Chak De India and Mary Kom have changed the thinking of citizens. In Indian politics, there are many women leaders but recently the films which are the mirror of society showing the women character as political leaders such as Rajneeti, Gulabi Gang. Through the research the impact and role of Cinema on society reflects what films have brought for the betterment and for upliftment of the society.

DISCUSSION AND CONCLUSION: -

The study demonstrates that a good cinema will educate, entertain and inspire people. The impact of Cinema is very broad, it makes us think and compassionate. cinema inspire people to help other and to do good for humanity. Cinema help in awareness and growth of so many charity organization and NGOs. Cinema is a way culture, beliefs, values and community. Cinema is very impressive in today's world and it is very impactful. It can change someone mind, feelings and opinion.

Beside these emotions cinema also help in shaping women life by raising awareness about issues with sexual violence, dowry system, child marriage, freedom of women, menstrual hygiene etc, not only in shaping women life it also help in shaping men life by raising issues like homosexuality, male sexual health, erectile problem etc. Cinema cause effect and shapes the social norm and receives input from the same audience. It can create consciousness about the value of sports, educations, arts and politics. it helps to rouse our felling of responsibility and empathy towards some situations.

From the last two decades movie making and viewing has changed significantly. Now, Bollywood produces films related to reality and related to social concern. In addition to entertainment and business, these movies are creating large impact on citizens related to social awareness. Films like Piku, Pink and Mardaani have broken the image of so called stereotyped Indian girl. Movies like No One Killed Jessica depicted that after a long battle fought in court of law for justice. 3 Idiots, Nil battey Sannata, Hichki, I am Kalam and many more uncountable Bollywood movies dealt with the education system in India for good or for bad. Highlighting the lives of typical Indian students who work really hard for their dreams.
In most of the cases study validates the positive impact of cinema on people.Cinema is one of the most relaxational activity which remains an influence on people,it works as an influential instrument on the picture of world,morals,stereotypes, the behavior of viewer etc. Cinema dedicates their content to create social awareness with entertainment to fight from taboos and it is most popular and effective way to raise awareness while entertaining.

Cinema help to accelerate unresolved justice, some inspire people to come forward for tackling social evils and some cinema give totally new directions to viewer.Basically, cinema help to make us more aware about situations and to understand the circumstances.It reflects our society and give us idea that how we have to deal with these things.

REFERENCES:

1. Iyengar, S.; Kinder, D. R. News That Matters: Television and American Opinion; University of Chicago Press: Chicago, IL, 2015.

2. Kaur, R.; Sinha Ajay, J.; Bollywood; Popular Indian Cinema Through a Transnational Lens/Edited by; Vol. 2005; SAGE: New Delhi, 2007, pp 23-33.

3.Eugene, V.; Beresin, M. D. The Impact of Media Violence on Children and Adolescents, Opportunities for Clinical. Interventions 2007, 2333.

4.CEDPA - Facts on Asia and Country Profile, Girls' Rights: Society's Responsibility; Taking Action against Sexual Exploitation and Trafficking: Mumbai, 1997.

5.Agarwal, N. P., Advanced Business Statistics; RBD Publications: Jaipur, 2011.

6.Ahmed, S. A., Bombay Films: The Cinema as Metaphor for Indian Society and Politics; University of Cambridge, 1992, pp 305-314.

7. Madan, T. N., Non-Renunciation: Themes and Interpretations of Hindu Culture; Oxford University Press: New Delhi, 1988, p 9. Murthy, N. V. Understanding Indian Cinema. In New Quest, 1988; Vol. 71 (Sept-Oct).

8.Burra, R., Film India: Looking Back 1896-1960, the Direction of Film Festivals, New Delhi.; ed; Central Statistical Organization, 1981 12,Women and Men in India 1998; Government of India: New Delhi, 1999.

9. Chitra Nair, T. N. N., Indian Cinema and the Global Perspective.

10.Murthy; C. S. H. N., Social Change Through Diffusion of Innovation in India Popular Cinema: An Analytical Study of Lage Raho Munna Bhai and Stalin. Asian Cinema2011, 269-289. 